\title{
KAJIAN KOMUNITAS EKOR PEGAS (COLLEMBOLA) PADA PERKEBUNAN APEL (MALUS SYLVESTRIS MILL.) DI DESA TULUNGREJO BUMIAJI KOTA BATU
}

\author{
Widyarnes Niwangtika, Ibrohim \\ Jurusan Biologi, Fakutas MIPA, Universitas Negeri Malang \\ Jalan Semarang 5 Malang 65145, Indonesia \\ Email korespondensil : widya.tikka@yahoo.com
}

\begin{abstract}
This research was conducted in order to determine composition, diversity, eveness, richness, important value index of springtail, and corellation between abiotic environment factor (temperature, $\mathrm{pH}$ and moisture) and diversity of springtail. Sampling was done using nilon sieve and pitfall trap, and this research was conducted in April-June 2014 in Tulungrejo village, Batu city. The result from this research, there are 11 species, 10 generas and 5 families of springtail. Diversity index of springtail both using nilon sieve and pitfall trap in apple plantation catagorized medium diversity. The result of important index value analyze showed that Entomobrya multifasciata has highest value. Based on regression analysis, abiotic factor has significant influence on diversity index of infauna.
\end{abstract}

Keywords: Comunity, Collembola, Apple Plantation.

\section{PENDAHULUAN}

Indonesia merupakan negara yang mempunyai bermacam-macam tanaman perkebunan. Tanaman perkebunan yang banyak dikembangkan di Indonesia salah satunya adalah tanaman buah dan buah apel (Malus sylvestris Mill.) merupakan salah satunya. Tanaman apel adalah tanaman yang berperan penting bagi pemenuhan gizi masyarakat dan pendapatan petani. Sejalan dengan pertumbuhan jumlah penduduk maka kebutuhan akan buah apel semakin meningkat, sehingga upaya peningkatan produksinya terus dilakukan (Sudiarso, 1994).Sampaisaatinibelumbanyakdaerah di Indonesia yang mengembangkan tanaman ini. Daerah yang telah dikenal memiliki wilayah pengembangan cukup luas adalah Kota Batu, Propinsi Jawa Timur (Triwiratno, 2008).

Perkebunan apel di Desa Tulungrejo Bumiaji salah satunya adalah yang dikelola Bapak Hadi. Perkebunan ini mulai ditanami Apel pada tahun 1996. Apel pada perkebunan ini terdiri dari dua varietas yaitu varietas Anna dan varietas Manalagi. Pada perkebunan apel ini pupuk yang digunakan adalah pupuk kombinasi yaitu pupuk kandang dan pupuk pabrik. Pupuk kandang yang digunakan berasal dari kotoran ayam potong sedangkan pupuk pabrik yang digunakan adalah pupuk ZA. Pemberian pupuk kombinasi pada perkebunan apel ini menurut petani dimaksudkan agar buah apel yang ditanam di perkebunan ini pertumbuhannya cepat dan buahnya terasa manis.

Pertumbuhan buah apel pada perkebunan umumnya dapat dipengaruhi oleh keadaan tanah yang subur. Hewan tanah memiliki kontribusi yang sangat besar untuk menentukan tingkat kesuburan tanah. Fauna tanah yang berperan sebagai detritivor dapat membantu dalam rehabilitasi tanah dan juga berpengaruh terhadap kehidupan disekitar fauna tanah itu berada (Takeda, 1981). Salah satu fauna tanah yang sangat berperan dalam menentukan keadaan tanah adalah Collembola. Collembola merupakan hewan mikro yang mempunyai persebaran luas. Habitat 
alami Collembola adalah permukaan tanah yang banyak mengandung humus dan serasah. Pada lahan yang mempunyai jumlah serasah melimpah komunitas Collembola akan lebih banyak. (Amir, 2008).

Collembolamerupakanhewandengan peran yang besar. Peran Collembola diantaranya adalah sebagai perombak bahan organik, pemakan jamur, indikator perubahan keadaan tanah, dan pemangsa (Suhardjono, dkk 2012). Penelitian yang banyak dilakukan saat ini yaitu fungsi Collembola sebagai indikator perubahan tanah. Collembola merupakan hewan yang mempunyai peran aktif dalam pengaturan perbandingan $\mathrm{C} / \mathrm{N}$ tanah. Perbandingan $\mathrm{C} / \mathrm{N}$ tanah merupakan parameter laju perombakan bahan organik. Kandungan bana organik yang tinggi dapat meningkatkan kepadatan populasi Collembola (Ummi, 2007). Namun disamping itu, tumbuhan tidak dapat mengasimilasi apabila perbandingan $\mathrm{C} / \mathrm{N}$ bahan organik dalam tanah lebih dari 20 (Takeda, 1981; Susetya, 2012).

Berdasarkan berbagai pertimbangan akan pentingnya penelitian mengenai komposisi populasi Collembola, maka diadakan penelitian ini untuk memberikan suatu pengetahuan baru mengenai organisme penyubur tanah sehingga dapat dimanfaatkan banyak kalangan dalam pengelolaan tanah.

\section{METODE}

Penelitian penelitian deskriptif

merupakan Tujuan dari penelitian ini adalah mendeskripsikan komunitas Collembola yang dikaji berdasarkan komposisi, keanekaragaman, kemerataan, indeks nilai penting serta pengaruh faktor abiotik terhadap keanekaragaman Collembola. Penelitian dimulai dari bulan April-Juni 2014. Pengambilan sampel dilakukan di perkebunan apel Desa Tulungrejo Kecamatan Bumiaji Kota Batu dan pengamatan sampel Collembola dilakukan di Laboratorium Biologi ruang 107 Fakultas Matematika dan Ilmu Pengetahuan Alam Universitas Negeri Malang. Objek yang diteliti dalam penelitian ini adalah Collembola yang hidup dipermukaan tanah (epifauna) yang tertangkap dengan pitfall trap dan Collembola yang hidup didalam tanah (infauna) yang tertangkap dengan metode isolasi basah pada perkebunan apel di Desa Tulungrejo Kecamatan Bumiaji Kota Batu.

Collembola yang ditemukan selama penelitian diidentifikasi morfologinya dan dijabarkan secara deskriptif, kemudian dihitung komposisi, keanekaragaman, kemerataan, dan kekayaan serta menganalisis hubungan faktor abiotik terhadap keanekaragaman. Data komposisi Collembola yang berhasil ditangkap disajikan berupa jumlah dari hasil identifikasi yang telah dilakukan pada masing-masing plot, sedangkan analisis data indeks Keanekaragaman menggunakan Indeks Keanekaragaman Shannon-Wienner, dan untuk mengetahui hubungan faktor abiotik terhadap kenekaragaman, kemerataan dan kekayaan digunakan analisis korelasi regresi.

\section{HASIL PENELITIAN}

1. Komposisi Spesies Ekor Pegas (Collembola) pada Perkebunan Apel

Hasil pengamatan komposisi

Collembola pada perkebunan apel secara keseluruhan ditemukan sebanyak 5 famili, 10 genus dan 11 Spesies. Famili yang ditemukan pada perkebunan apel selama penelitian ini adalah Hypogastruridae, Neanuridae, Tomoceridae, Isotomidae, dan Entomobrydae. Jumlah famili yang paling banyak ditemukan adalah famili Entomobrydae. Hasil pengamatan 
komposisi Collembola epifauna perkebunan apel dapat dilihat pada Tabel dan infauna yang ditemukan pada 1 dan 2.

Tabel 1. Komposisi Collembola Epifauna pada Perkebunan Apel

\begin{tabular}{clll}
\hline No & Famili & Genus & Nama Spesies \\
\hline 1 & Tomoeridae & Tomocerus & Tomocerus sp \\
2 & Isotomidae & Pseudisotoma & Pseudisotoma sp \\
3 & Entomobrydae & Ascocyrtus & Ascocyrtus bispinosus \\
4 & Entomobrydae & Entomobrya & Entomobrya multifasciata \\
5 & Entomobrydae & Entomobrya & Entomobrya proxima \\
6 & Entomobrydae & Heteromurus & Heteromurus sp \\
7 & Entomobrydae & Homidia & Homidia sp \\
\hline
\end{tabular}

Tabel 2. Komposisi Collembola Infauna pada Perkebunan Apel

\begin{tabular}{clll}
\hline No & Famili & Genus & Nama Spesies \\
\hline 1 & Hypogastruridae & Hypogastrura & Hypogastrura sp \\
2 & Neanuridae & Neanura & Neanura sp \\
3 & Entomobrydae & Entomobrya & Entomobrya multifasciata \\
4 & Entomobrydae & Sinella & Sinella sp \\
5 & Entomobrydae & Rambutsinella & Rambutsinella sp \\
\hline
\end{tabular}

2. Keanekaragaman, Kemerataan dan didapatkan hasil kemerataan jenis Kekayaan jenis Collembola pada la- epifauna dan infauna yang tergolong kecil han Perkebunan Apel

Hasil analisis indeks keanekaragaman hasil kekayaanjenis epifauna danepifauna Shannon-Wienner didapatkan hasil yang tergolong rendah. Hasil analisis keanekaragaman jenis epifauna dan indeks keanekaragaman, kemerataan dan infauna yang tergolong sedang. kekayaan jenis Collembola dapat dilihat Sedangkan untuk indeks kemerataan pada Tabel 3 berikut.

Tabel 3. Indeks Keanekaragaman, Kemerataan dan kekayaan Collembola pada Perkebunan Apel

\begin{tabular}{lccc}
\hline & Keanekaragaman $\left(\mathbf{H}^{\prime}\right)$ & Kemerataan (E) & Kekayaan (R) \\
\hline Epifauna & 1,627 & 0,217 & 1,476 \\
Infauna & 1,531 & 0,253 & 1,398 \\
\hline
\end{tabular}

Keterangan :

$\begin{array}{ll}\mathrm{H}^{\prime} & : \text { Indeks Keanekaragaman Shanon-Wiener } \\ \mathrm{E} & : \text { Indeks kemerataan Evennes } \\ \mathrm{R} & : \text { Indeks kekayaan Richness } \\ \mathrm{E}<0,4 & : \text { Kemerataan populasi kecil } \\ 0,4<\mathrm{E}<0,6 & : \text { Kemerataan populasi sedang } \\ \mathrm{E}>0,6 & : \text { Kemerataan populasi tinggi } \\ \mathrm{R}_{1}<3.5 & : \text { Kekayaan jenis yang tergolong rendah, } \\ \mathrm{R}_{1}=3.5-5.0 & : \text { Kekayaan jenis tergolong sedang } \\ \mathrm{R}_{1}>5.0 & : \text { Kekayaan jenis tergolong tinggi (Megurran, 1988). }\end{array}$


3. Indeks Nilai Penting Spesies Ekor Pegas (Collembola) pada Perkebunan Apel.

Hasil analisis indeks nilai penting diketahui spesies yang paling dominan adalah Entomobrya multifasciata dari famili Entomobrydae. Nilai tertinggi pada analisis indeks nilai penting ini menunjukkan bahwa spesies Entomobrya multifasciata merupakan spesies yang mempunyai peranan dan penguasaan paling besar dalam komunitas Collembola di perkebunan apel. Hasil analisis indeks nilai penting (INP) Collembola epifauna dan infauna pada perkebunan apel dapat dilihat pada Tabel 4 berikut.

Tabel 4. Indeks Nilai Penting Tertinggi pada Collembola di Perkebunan Apel

\begin{tabular}{lllllll}
\hline No & Famili & Nama Spesies & $\begin{array}{c}\text { Jumlah } \\
\text { spesies } \\
\text { infauna }\end{array}$ & $\begin{array}{c}\text { INP } \\
\text { infauna }\end{array}$ & $\begin{array}{c}\text { Jumlah } \\
\text { spesies } \\
\text { epifauna }\end{array}$ & $\begin{array}{c}\text { INP } \\
\text { epifauna }\end{array}$ \\
\hline 1. Entomobrydae & $\begin{array}{l}\text { Entomobrya } \\
\text { multifasciata }\end{array}$ & 168 & 81,55 & 364 & 46,71714 \\
\hline
\end{tabular}

4. Hubungan Faktor Abiotik Terhadap Keanekaragaman, Kemerataan dan Kekayaan Jenis Collembola pada Perkebunan Apel

Hasil analisis terhadap faktor abiotik yang berperan dalam keanekaragaman Collembola diketahui kelembaban merupakan faktor dengan sumbangan efektif terbesar yakni $45 \%$. Faktor abiotik yang diukur dalam penelitian ini meliputi $\mathrm{pH}$, suhu dan kelembaban tanah. Hasil analisis tersebut dapat dilihat pada tabel 5.

Tabel 5 Sumbangan Efektif Tiap Variabel

\begin{tabular}{cll}
\hline No & Variabel bebas & $\begin{array}{l}\text { Sumbangan } \\
(\mathbf{\%})\end{array}$ \\
\hline 1 & $\mathrm{pH}$ & 4,953 \\
2 & Suhu & 16,3134 \\
3 & Kelembaban & 45,0072 \\
\hline & Jumlah & 56,3676 \\
\hline
\end{tabular}

5. Hubungan Kandungan C/N Organik Terhadap Keanekaragaman Kemerataan dan Kekayaan Jenis Collembola pada Perkebunan Apel

Hasil analisis korelasi yang dilakukan didapatkan hasil bahwa kandungan $\mathrm{C} / \mathrm{N}$ organik tanah mempunyai pengaruh terhadap kemerataan dan kekayaan infauna dan epifauna. Sedangkan kandungan $\mathrm{C} / \mathrm{N}$ organik serasah tidak berpengaruh pada keanekaragaman, kemerataan dan kakayaan jenis infauna maupun epifauna. Hasil analisis kandungan $\mathrm{C} / \mathrm{N}$ organik pada tanah dan serasah dapat dilihat pada tabel 6 .

Tabel 6.Rerata Hasil Pengukuran Bahan Organik Tanah dan Serasah di Perkebunan Apel Tiap

\begin{tabular}{|c|c|c|c|c|}
\hline No & Sampel & C ( $(\%)$ & N (\%) & Rasio C/N \\
\hline 1 & $\begin{array}{l}\mathrm{S} \text { a m p e } 1 \\
\text { tanah }\end{array}$ & 16,02 & 0,65 & 24 \\
\hline 2 & $\begin{array}{l}\mathrm{S} \text { a m p e } 1 \\
\text { serasah }\end{array}$ & 30,94 & 1,66 & 18,67 \\
\hline
\end{tabular}

\section{PEMBAHASAN}

Penelitian yang dilakukan terhadap Collembola pada perkebunan apel menunjukkan bahwa komposisi secara keseluruhan terdiri dari 11 spesies, 10 genus dan 5 famili. Collembola yang banyak ditemukan pada perkebunan apel adalah Collembola dari famili Entomobrydae yang termasuk dalam ordo Entomobryomorpha. Famili Entomobrydae merupakan famili Collembola yang banyak hidup dipermukaan tanah dan serasah yang mulai membusuk (Jumar, 2000). Collembola pada umumnya dikenal sebagai organisme yang hidup di tanah serta mempunyai peranan penting dalam perombak bahan organik (Indriyati dan 
Wibowo, 2008).

Hasil analisis indeks keanekaragaman Collembola menggunakan indeks Shanon-Wiener, pada perkebunan apel baik infauna $(1,6)$ maupun infauna $(1,5)$ dikategorikan rendah (Megurran, 1988). Keanekaragaman yang rendah dapat disebabkan karena adanya pengaruh faktor abiotik serta ekosistem yang terkendali misalnya dengan pengolahan lahan yang dilakukan oleh petani setempat (Dharmawan dkk., 2005). Hasil analisis indeks kemerataan pada penelitian ini diperoleh indeks kemerataan sebesar 0,21 pada epifauna dan 0,25 pada infauna. Nilai tersebut tergolong kategori kemerataan populasi kecil (Megurran, 1988). Kemerataan jenis yang rendah dapat diakibatkan karena tiap spesies mempunyai jumlah individu yang relatif berbeda-beda dan tidak ada yang mendominasi (Krebs, 1989; Mas'ud dkk., 2011). Kekayaan jenis Collembola pada perkebunan ini menunjukkan hasil pada epifauna diperoleh nilai sebesar 1,4 dan pada infauna diperoleh nilai sebesar 1,3. Nilai-nilai tersebut tergolong dalam kekayaan jenis rendah (Megurran (1988)).

Collembola jenis epifauna dan infauna yang didapatkan pada penelitian ini memiliki jumlah yang berbedabeda. Jumlah individu Collembola yang ditemukan sebagian besar merupakan epifauna. Collembola epifauna hidup dipermukaan tanah dan serah dan memiliki ciri furca berkembang dengan baik (Borror, 1992). Collembola yang banyak ditemukan berasal dari spesies Entomobrya multifasciata dengan INP 81,55 . Jenis yang mempunyai indeks nilai penting terbesar merupakan jenis yang paling dominan atau berarti pula jenis tersebut mempunyai tingkat kesesuaian terhadap tempat hidup dibandingkan dengan jenis lain (Soerianegara dan Indrawan, 2002). Namun terdapat beberapa jenis epifauna yang ditemukan berada dalam tanah. Hal tersebut dapat disebabkan berbagai faktor salah satunya karena tingkat kekeringan atau kebasahan tanah yang berlebihan serta suhu lapisan permukaan tanah yang ekstrim tinggi atau rendah (Haryoko, 2010).

Hasil analisis regresi faktor abiotik terhadap keanekaragaman, kemerataan dan kekayaan jenis Collembola pada perkebunan apel diketahui bahwa faktor abiotik mempunyai pengaruh yang signifikan terhadap keanekaragaman Collembola yang ditemukan di dalam tanah (infauna). Variabel yang mempunyai sumbangan efektif tertinggi dan berarti mempunyai peranan paling besar terhadap keanekaragaman infauna adalah kelembaban tanah. Kelembaban tanah mengindikasikan kandungan air tanah yang berada disekitar tempat hidup Collembola. Kelembaban mempunyai peran penting dalam menentukan pola distribusi Collembola (Christiansen,1990; Suhardjono, 2012).

Hasil analisis korelasi terhadap kandungan bahan organik dan keanekaragaman Collembola menunjukkan adanya hubungan anatara keduanya. Artinya kandungan $\mathrm{C} / \mathrm{N}$ pada tanah memiliki hubungan dengan homogenitas dan cacah individu Collembola dalam penelitian. Kandungan $\mathrm{C} / \mathrm{N}$ pada tanah merupakan kandungan yang paling banyak diperlukan oleh mikroorganisme yang mendekomposisi bahan organik (Susetya, 2012). Mikroorganisme dekomposer seperti jamur dan bakteri merupakan makanan utama bagi Collembola, sehingga keberadaannya secara tidak langsung dapat mempengaruhi kemerataan Collembola (Ummi, 2007). Pada pengamatan pengaruh $\mathrm{C} / \mathrm{N}$ serasah terhadap keanekaragaman, kemerataan dan kekayaan didapatkan hasil kandungan $\mathrm{C} / \mathrm{N}$ serasah tidak mempunyai hubungan pada ketiga 
variabel. Hal tersebut dikarenakan sampel serasah yang diambil selama penelitian mempunyai keadaan yang berbeda. Sebagian serasah ada yang sudah membusuk dan sebagian serasah belum mengalami pembusukan. Collembola umumnya lebih menyukai habitat dengan serasah yang telah membusuk dan terfermentasi. Serasah yang masih segar atau baru jatuh dari pohon umumnya tidak menjadi pilihan Collembola karena teksturnya yang masih keras sehingga membuat Collembola belum mampu menggigitnya (Suhardjono dkk, 2012).

\section{KESIMPULAN}

1. Komposisi Collembola pada lahan perkebunan apel yang ditemukan terdiri dari 5 famili,10 genus dan sebanyak 11 spesies. Spesies paling yang banyak ditemukan adalah jenis Entomobrya multifasciata.

2. Nilai indeks keanekaragaman Collembola infauna dan epifauna termasuk kategori keanekaragaman rendah.

3. Indeks nilai penting (INP) spesies tertinggi pada penelitian ini dimiliki oleh Entomobrya multifasciata. Jenis yang mempunyai indeks nilai penting terbesar, merupakan jenis yang paling dominan atau berarti pula jenis tersebut mempunyai tingkat kesesuaian terhadap tempat hidup dibandingkan dengan jenis lain.

4. Faktor abiotik memberikan pengaruh signifikan terhadap keanekaragaman jenis Collembola dan variabel bebas yang paling mempengaruhi adalah kelembaban tanah.

5. Kandungan $\mathrm{C} / \mathrm{N}$ organik mempunyai hubungan terhadap keanekaragaman, kemerataan dan kekayaan jenis Collembola. Sedangkan Kandungan $\mathrm{C} / \mathrm{N}$ serasah tidak mempunyai hubungan terhadap keanekaragaman, kemerataan dan kekayaan jenis Collembola.

\section{SARA N}

1. Perlu dilakukan penelitian lanjutan tentang komunitas Collembola dengan rentang waktu yang lebih panjang misalnya membandingkan antara musim hujan dan kemarau.

2. Perlu dilakukan penelitian lanjutan mengenai peranan faktor abiotik terhadap komposisi ekor pegas (Collembola) pada perkebunan apel.

\section{DAFTAR RUJUKAN}

Amin, F. 2007. Penerapan Pengendalian Hayati Hama Terpadu Terhadap Keanekaragaman Arthropoda Pada Pertanaman Kedelai. Skripsi. Malang: Universitas Brawijaya.

Dharmawan, A. Tuarita, H. Ibrohim. 2005. Ekologi Hewan. Malang: UM Press.

Haryoko, Wendy. 2010. Keanekaragaman dan Distribusi Collembola di Permukaan Lantai Gua Tegoguo di Kaligesing Purworejo Jawa Tengah. Skripsi : Tidak Diterbitkan.

Krebs, J.C. 1989. Ecological Methodology. New York. Herper Collins Peblisher.

Magurran, Anne E. 1988. Ecological Diversity and Its Measurement. New Jersey: Princeton University Press.

Mas'ud A, Sundari. 2011. Kajian Struktur Komunitas Epifauna Tanah di Kawasan Hutan Konservasi Gunung Sibela Halmahera Selatan Maluku Utara. Bioedukasi Volume 2, nomor 1: 7-15.

Soerianegara, I dan A. Indrawan. 2002. Ekologi Hutan Indonesia. Bogor : Institut Pertanian Bogor Press.

Suhardjono, Yayuk Rahayuningsih. Deharveng, Louis. Bedos Anne. 
2012. Collembola (Ekor Pegas). Triwiratno, A. 2008. Koleksi Varietas Baru Cibubur: Vegamedia. Apel dari Negara Belanda. Majalah

Suin, N.M. 1997. Ekologi Hewan Tanah. Jakarta: Penarbit Bumi aksara.

Susetya, Darma. 2012. Panduan Lengkap Pembuatan Pupuk Organik. Yogyakarta: Pustaka Baru Press.

Takeda, H. 1981. Effect of Shiffing Cultivation on The Soil MesoFauna with Special References to Collembolan Population in NorthEast Thailand Memoir of College of Agriculture Kyoto University. 18 : $44-60$
Sinar Tani Edisi : 17. Batu : Balai Penelitian Tanaman Jeruk dan Buah Subtropika.

Ummi, R.Z. 2007. Studi Keanekaragaman Serangga Tanah di UPT Balai Konservasi Tumbuhan Kebun Raya Purwodadi-LIPI. Skripsi. Malang: Universitas Islam Negeri Malang. 